\title{
Produção in vitro de embriões de ovinos: uma visão crítica do método e de seu resultado a campo
}

\author{
Anneliese de Souza Traldi ${ }^{1}$
}

\author{
${ }^{1}$ Departamento de Reprodução Animal - FMVZ - USP.
}

RESUMO - A metodologia de produção in vitro de embriões de ovinos implica no desenvolvimento de meios de maturação, fertilização e cultivo que permitam aumentar a taxa de clivagem e desenvolvimento, tanto para o investimento biotecnológico em programas comerciais, quanto para sua utilização em clonagem e transgenia dessa espécie animal. Do ponto de vista da pesquisa, os ovócitos podem ser obtidos pelas técnicas de punção e slicing a partir de ovários oriundos de matadouros, ou através de aspiração folicular por laparoscopia. Como vantagem, este método permite o uso de uma mesma doadora estimulada hormonialmente em intervalos periódicos, mantida sob rigoroso controle sanitário, o que é de vital importância para a produção de biofármacos em programas que utilisem os ovinos como modelo biológico. Por outro lado, em nosso país a demanda pela multiplicação de animais de alto valor genético, seja pela produtividade ou pelo elevado valor comercial dos mesmos, impõe o desenvolvimento, adaptação e otimização das diferentes metodologias desenvolvidas ao longo dos ultimos anos em laboratórios de referência mundiais. Nesse contexto, cresce de importância o perfeito conhecimento da fisiologia dessa espécie e das raças criadas em nosso país, e da problemática da produção in vitro de seus embriões. Respeitando essas premissas, gerar o desenvolvimento de protocolos que permitam não apenas aumentar a população de ovócitos passíveis de maturaçãoin vitro, mas de sua competência ao desenvolvimento ao estágio de blastocisto, ou, alternativamente, sua transferência a receptoras em estágios precoces do desenvolvimento, evitando assim as conhecidas perdas durante o desenvolvimento in vitro, e o baixo percentual de gestações que chegam a termo, com cordeiro saudáveis. Trata-se de um desafio, que já apresenta os primeiros resultados em nosso país, tanto na produção comercial de embriões produzidos in vitro, quanto em programas de clonagem e transgenia.

Palavras-chave: embrião, fertilização in vitro, oócito, ovinos

\section{In vitro embryo production in ovine: critical vision of the method and of the field results}

\begin{abstract}
The methodology of in vitro embryo production in ovine requires the development of maturation, fertilization and culture media, in order to increase cleavage and development rates. This, in turn, would improve the implement of biotechnological programs for commercial purposes, as well as the use of this technique for cloning and transgenesis in this species. From the point of view of research, the oocytes can be obtained by puncture or slicing of ovaries collected from abattoirs, or by laparospic follicular aspiration (LOPU). One of the advantages of the LOPU is allowing the use of the same hormonally stimulated donor several times in periodic intervals. This could be extremely important, for instance, when using the ovine as a biological model for the production of biodrugs, as long as animals are submitted to a strict sanitary control. On the other hand, in Brazil, due to their improved productivity or high commercial value, there is a demand for animals of high genetic value, which requires the development, adaptation and maximization of the different methodologies designed throughout the last years in reference laboratories worldwide. In this context, the perfect knowledge of the ovine physiology, especially from the breeds raised in Brazil, as well as the problems of the ovine in vitro embryo production are becoming more and more important. Therefore, it is fundamental to create protocols to allow not only the increase on the population of oocytes with enough quality to undergo in vitro maturation, but competence to reach the blastocyst stage, or alternatively, the transference of early stages embryos to the recipients, avoiding the common embryo losses during the in vitro development and the low rates of full-term pregnancies, with healthy lambs. The first results of this challenge are already being observed in Brazil, not only in the in vitro embryo production for commercial purposes, but in programs of cloning and transgenesis.
\end{abstract}

Key Words: embryo, in vitro fertilization, oocyte, ovine 


\section{Introdução}

Condições de maturação (MIV), fertilização (FIV) e cultivo in vitro (DIV) foram estudadas em pequenos ruminantes por diferentes grupos de pesquisadores (Mermillod et al., 1996; Holm et al., 1996; Crozet, 1997; Guler et al., 2000; Thompson, 2000, Rizos et al., 2002; Cognié et al. 2003; Ptak et al, 2006; Kelly et al., 2008), adequando-se inicialmente protocolos adaptados a partir daqueles de bovinos, o que demonstrou uma marcante diferença entre as espécies.

O uso de ovários oriundos de matadouros, modelo clássico para obtenção de oócitos para pesquisa, no qual não se conhece o exato estado fisiológico e sanitário dos animais, foi gradativamente substituído pela aspiração folicular por laparoscopia (LOPU) a partir dos resultados e técnica descritos pioneiramente por Snyder \& Dukelow em 1974 e por Baldassarre et al. (1994) e Tervit et al (1992) no início década de 90. Como vantagem, esse método permite o uso da mesma doadora por diversas vezes e o pleno controle sanitário das mesmas, tanto para o investimento biotecnológico em programas comerciais de multiplicação, quanto para sua utilização em clonagem e transgenia dessa espécie animal, no qual o pequeno ruminantes é usado como biorreator na produção de proteínas de interesse farmacêutico, expressas em seu leite (Baldassarre \& Karatzas, 2004).

Embora mudanças nos meios de maturação e de cultivo tenham melhorado acentuadamente a produçãoin vitro de blastocistos dessa espécie nos últimos 10 anos, a taxa de sobrevivência embrionária e viabilidade pós-natal ainda é baixa comparativamente a caprinos e bovinos, fato a ser levado em consideração quando do uso da PIV como ferramenta de multiplicação de animais geneticamente superiores.

\section{Obtenção de ovócitos}

Quando o intuito é o desenvolvimento e estudo de diferentes meio que otimizem a produção de embriões in vitro (PIV), bem como seu metabolismo, e em experimentos de clonagem ou transgenia, os ovócitos podem ser obtidos pelas técnicas de punção e slicing (Keskintepe et al., 1994) a partir de ovários oriundos de matadouros. Porém, quando o objetivo é a produção comercial de embriões com multiplicação de animais de reconhecido mérito genético, ou em programas comerciais de animais geneticamente modificados, a aspiração folicular por laparoscopia (LOPU) é a ferramenta ideal, por se tratar de técnica pouco invasiva, que permite a obtenção de ovócitos de uma mesma doadora estimulada hormonialmente em intervalos periódicos, e consequentemente de oócitos passíveis de maturação in vitro (Baldassarre et al., 2002), o que pode igualmente ser feito em fêmeas não estimuladas sem diferença nas taxas de clivagem ou de formação de blastocistos (Morton et al., 2005 a,b).

Para obtenção de maior número de folículos a serem aspirados utilizando a LOPU e redução do número oócitos com cúmulus expandido inviáveis à MIV foram testados diferentes tratamentos gonadotróficos sendo o de eleição denominado "one-shot" (Baldassarre et al., 2002) por promover menor intervalo entre a estimulação hormonal e a LOPU (36 horas) utilizando 70 a 80 mG NHI-FSH-P1 e 300UI de eCG em uma única aplicação. O pessário vaginal colocado no primeiro dia do tratamento é retirado no momento da punção, bloqueando dessa maneira o pico endógeno de LH e ovulações, e favorecendo a obtenção de oócitos em estágio de vesícula germinativa, adequados à maturação in vitro (Morton et al, 2005a). Apenas são puncionados folículos entre três e $5 \mathrm{~mm}$ de diâmetro, que possuem maior camada de cúmulus. Oócitos de pequenos folículos $(2 \mathrm{~mm})$ tem baixa competência para o desenvolvimento in vitro, uma vez que proteínas e fatores de maturação são sintetizados unicamente durante a fase final do crescimento folicular (Crozet et al., 1995; Mermillod et al., 1999; Mermillod et al., 2008).

Da habilidade na manipulação do instrumental, e da resposta do animal ao tratamento hormonal depende o número de folículos puncionados e de oócitos recuperados, que varia de quatro a 10 por doadora, com taxa de colheita de 33 a 60\% (Alberio et al., 2002; Gibbons et al., 2007). Níveis elevados de recuperação por LOPU de 13,4 oócitos por doadora em 1580 aspirações em programa comercial de transgenia em caprinos (Baldassarre et al., 2004) e de 14,3 em 587 seções de LOPU comercial em ovinos em nosso país (Basso et al., 2008) demonstram que protocolos de estimulação hormonal e a técnica de aspiração, bem como o intervalo entre aspirações e o número de repetições por doadora devem ser testados e definidos de acordo com raça, época do ano, espécie e objetivo a ser alcançado (Pierson et al., 2004).

Duas características físicas afetam a recuperação dos oócitos: o fluxo de aspiração e o diâmetro da agulha de punção (Rodriguez et al., 2006; Gibbons et al., 2008)). Em ovinos são utilizadas bombas de aspiração com pressão entre 25 a 100 mMHg (Baldassarre et al., 1996; Cognié et al., 2004; Cox \& Alfaro, 2007; Morton et al., 2008a) ou 10 a 20 mL H2O min-1 (Alberio et al., 2002; Cognié et al., 2004) ou 
50 a 70 gotas/min (Baldassarre et al., 2003). A agulha normalmente utilizada varia de 18 a $21 \mathrm{G}$, com taxas de recuperação de 40 a 90\% assim (Cognié et al., 2004; Morton et al. 2005a; Rodriguez et al., 2006; Cox \& Alfaro, 2007; Gibbons et al., 2007). O comprimento e diâmetro do bizel são igualmente importantes, para que não ocorra perda de líquido folicular e consequientemente dos ovócitos no momento da punção (Rodriguez et al., 2006). Em programa de clonagem ovina em nosso país (Traldi et al., 2007), a adaptação de agulha de punção folicular bovina de 19G permitiu recuperação de 51 a $86 \%$ de oócitos.

\section{Produção dos embriões in vitro}

A metodologia de produção in vitro de embriões de ovinos implica no desenvolvimento de meios de maturação, fertilização e cultivo que permitam aumentar a taxa de clivagem e desenvolvimento, tanto para o investimento biotecnológico em programas comerciais, quanto para sua utilização em clonagem e transgenia dessa espécie animal.

A maturação in vitro representa a primeira etapa desse processo. A maturação nuclear refere-se à habilidade do núcleo em retomar a meiose, ou seja, chegar ao estágio de metáfase da segunda divisão meiótica-Meta II, o que pode ser observado por microscopia através da extrusão do primeiro corpúsculo polar (Mermillod et al., 1996, Crozet, 1997), o que ocorre entre 16 e 24 h após o início da MIV (Cognié et al., 2003). Diferentemente, a maturação citoplasmática não pode ser identificada somente pela organização de suas organelas, e sim em níveis moleculares (Duranthon \& Renard, 2001; Mermillod et al., 2008). Oócitos com citoplasma irregular, desnudos ou semi-desnudos são eliminados e apenas colocados em maturação os de citoplasma levemente granulado e múltiplas camadas de cúmulus (COC Grau I) ou com no mínimo uma a três camadas uniformes de células do cúmulus (Grau II) ( Cognié et al., 2004, Baldassarre et al, 2003).

Para induzir a maturação nuclear e citoplasmática, devem ser adicionados ao meio fatores como o FSH, LH, estradiol, cysteamina, glutamina, piruvato de sódio, soro de fêmea em estro, soro fetal (FCS) ou fluido folicular de folículos não atrésicos, além de condições ambientais adequadas como a tensão de $\mathrm{CO}_{2}, \mathrm{O}_{2}$, temperatura, umidade e tempo de maturação nuclear in vitro (Cognié et al., 2003; Cognié et al., 2004; Morton et al, 2005b, Leoni et al., 2007; Pereira-Bonnet et al, 2008) e, alternativamente, fatores crescimento, como IGF, eGF, LIF e peptídeos intra-ovarianos em meios semidefinidos, com soro albumina bovina (BSA) ou definidos, sem presença de BSA ou FCS (Guler et al., 2000; Cognié et al., 2004; Ptak et al., 2006).
Melhorias no meio de maturação como a associação de estradiol, cysteamina e gonadotrofinas recombinantes ao meio suplementado com BSA (Accardo et al., 2004) repercutem diretamente na taxa de formação de blastocistos (42\%) em relação ao número de ovócitos colocados em maturação e elevada taxa de sobrevivência embrionária pós-transferência (52-67\%), semelhante àquela desejável a partir de embriões produzidos in vivo, a partir de fêmeas superovuladas.

Os oócitos maturados devem ser delicadamente pipetados para eliminação do cumulus antes de serem transferidos no meio de fertilização. O meio empregado para a FIV deve ser capaz de promover a capacitação espermática, a união dos gametas e o início do desenvolvimento embrionário Previamente, o sêmen é descongelado e centrifugado em gradiente de Percoll (45\%/90\%) ou em meio TALP onde os espermatozóides vivos são recuperados, diluídos para uma concentração de $10 \times 10^{6} / \mathrm{ml}$ e incubados durante $1 \mathrm{~h}$ no meio de capacitação em estufa seca, a 39,0 $0^{\circ}$ O meio de capacitação contém preferencialmente 2 a $10 \%$ soro de ovelha em estro (SOE), que remove a membrana de colesterol dos espermatozóides, favorecendo sua capacitação e conseqüente fecundação (Cognié et al., 2004; Baldassarre et al., 2003). Alternativamente, podemser usados $5 \mu \mathrm{g} / \mathrm{mL}$ de heparina como agente capacitante (Cognié et al, 2004).

A FIV é feita em gotas onde são inseminados 0,5 a $1 \times 10^{6}$ espermatozóides $/ \mathrm{ml}$, mantidas em incubação durante 17 a 18 horas a $39^{\circ} \mathrm{C}$ em atmosfera úmida com 5 a $6 \%$ de $\mathrm{CO}^{2}$ (Baldassarre et al., 2003; Cognié et al., 2003; Morton et al., 2005a).

O cultivo embrionário pode ser feito em meios definidos, semi-definidos com BSA ou FCS ou em co-cultivo com células tubáricas ou da granulosa (Cognié et al., 2003; Garcia-Garcia et al., 2006). O mais utilizado é o meio SOF- Fluido Sintético do Oviduto, acrescido de amino-ácidos e BSA, que mimetiza o ambiente intratubárico nas primeiras fases do desenvolvimento embrionário (Cognié et al., 2004). Nele o conjunto de oócitos submetidos à FIV são transferidos (D.0) e mantidos em microgotas cobertas por óleo mineral a $39^{\circ} \mathrm{C}$ em atmosfera úmida a $5 \%$ de $\mathrm{CO} 2,5$ a $7 \%$ de $\mathrm{O} 2$ e 88 a $90 \%$ de N2 7 a 8 dias, para avaliação do desenvolvimento e capacidade de eclosãoin vitro (Cognié et al., 2004; Morton et al., 2005b; Garcia-Garcia et al., 2007; Pereira-Bonnet et al., 2008). Uma suplementação com FCS no D.2 do DIV promove maior viabilidade dos embriões pós-transferência (Cognié et al., 1999) e o meio pode ser trocado a cada dois dias (Holm et al., 1996). 
Sob adequado controle laboratorial, taxas de 49,8\% de clivagem $48 \mathrm{~h}$ pós inseminação, $51 \%$ de blastocistos no D. 8 e $86,6 \%$ de eclosão in vitro podem ser atingidas, o que equivale a um percentual de apenas $24,1 \%$ de blastocistos desenvolvidos in vitro em relação ao número total de oócitos colocados em maturação, ou seja, uma baixa rentabilidade do processo (Garcia-Garcia et al., 2007).

No ovino, ocorre com frequência fragmentação citoplasmática que se confunde com clivagem, e que resulta em baixo percentual de blastocistos após sete a oito dias de cultivo. Maior atenção ao fato deve ser tomada quando da transferência de estruturas pela via intra-tubárica nas primeiras 48 horas após a FIV. Esses embriões recém clivados terão entre duas a seis células, enquanto os fragmentados se assemelham a mórulas jovens, de citoplasma homogêneo, totalmente incompatível com a cinética do desenvolvimento in vitro.

O aprimoramento da PIV ovina passa pelo constante desafio de se encontrar o melhor meio e as melhores condições in vitro para cada uma de suas etapas, que permita que o maior número possível de oócitos colocados em MIV clivem, ultrapassem o estágio de bloqueio embrionário e reassumam o desenvolvimento até sua eclosão em cultivo, mimetizando a vida livre intra-uterina.

\section{Perspectivas da PIV ovina}

Diversas publicações e excelentes revisões em revistas especializadas relatam o nascimento de bezerros e cordeiros produzidos in vitro com tamanho e peso anormal e excessivo (Holm et al., 1996; Sinclair et al, 1999; Thompson, 2000; Farin et al., 2001; Cognié et al., 2004), além de malformações como agnatia, e baixa viabilidade no período pós-natal, possivelmente devido a fatores inerente aos componentes dos meios de desenvolvimentoinvitro e do tempo de permanência no meio de cultivo com soro, que causa alterações morfológicas e bioquímicas nos embriões em desenvolvimento (Thompson et al, 1995). Paralelamente, em alguns casos não há sinalização do parto, fazendo que a gestação ultrapasse o tempo normal da espécie com conseqüente morte do feto, mesmo quando de indução farmacológica do parto. Nesses casos, semelhante a animais oriundos de clonagem por transferência de núcleo de célula somática (NTSC) notase ao nascimento gigantismo fetal, um maior diâmetro do cordão umbilical, e na maioria dos casos, morte por deficiência respiratória (Loi et al., 2006; Palmieri et al., 2007). Em um programa de transferência de 76 embriões PIV vitrificados de ovinos a 34 receptoras, dois dos apenas sete nascidos apresentavam tamanho e peso excessivos
(9 e 9,6 kg), além de agnatia. Todos os demais cordeiros morreram no período peri-natal, fato que não ocorreu com nenhum dos 13 cabritos nascidos de 43 embriões PIV vitrificados simultaneamente, produzidos sob idênticas condições in vitro (Traldi et al., 1999).

$\mathrm{Na}$ literatura associam-se esses distúrbios de desenvolvimento ao soro fetal de bezerros adicionado ao meio de cultivo pós-clivagem. Igualmente questiona-se sobre a necessidade ou não da presença de FCS como fonte de proteína ao meio, uma vez que nota-se um aumento no volume da blastocele, sem aumento correspondente do número de blastômeros. Uma diminuição no tempo de permanência dos embriões em cultivo poderia minimizar possíveis alterações tanto no botão embrionário, quanto no trofectoderma, e reduzir a incidência de anomalias de desenvolvimento. Os embriões seriam transferidos às receptoras pós-clivagem, em estágio de 2 a 4 células, no terço superior da ampola tubárica, através de procedimento cirúrgico ou semi-laparoscópico. Através dessa técnica, nossa equipe obteve o nascimento do primeiro clone ovino do país, em 2007 (Traldi et al., 2007) e tem gerado excelente resultado de multiplicação de caprinos transgênicos (Reggio et al., 2001; Baldassarre et al., 2003).

Porém, mesmo com a transferência de estruturas recém clivadas, o resultado final pode ser aquém do desejado comparativamente a um programa de tradicional de transferência de embriões (TE) de ovinos, no qual se busca uma média de cinco embriões viáveis por doadora superovulada. Resultados de FIV comercial apontam para as falhas citadas. Apesar de estimulação hormonal e LOPU, e do alto percentual de clivagem dos ovócitos (78\%- 43 clivados/55 maturados) de fêmeas de alto mérito genético, uma baixa taxa de sobrevivência embrionária (30,2\%-13/43) somado a alta mortalidade peri-natal $(61,5 \%)$ resultou em apenas 1,6 cordeiros nascidos por doadora tratada e 0,6 cordeiros saudáveis e vivos aos dois meses de idade, por doadora. Além da falha na sinalização do parto, e da necessidade de indução farmacológica do mesmo para evitar perdas, alguns cordeiros apresentaram peso acima da média da raça (6 a 7,5kg) e problemas respiratórios, característicos de cordeiros oriundos de PIV, resultando em baixa eficácia do programa, de apenas 11,6\% (5/43), 9,1 (5/ 55) e 7,0 (5/71) crias saudáveis em relação ao número de embriões transferidos, oócitos levados à MIV e oócitos recuperados na LOPU, respectivamente .

Melhores resultados de sobrevivência pós-natal, próximos àqueles obtidos em programas de TE, foram obtidos por Cox \& Alfaro (2007)que, para evitar os inconvenientes do desenvolvimento in vitro, transferiram embriões recém 
clivados, 48h após a FIV para a trompa ovelhas ligadas cirurgicamente para que as estruturas permanecessem incubadas durante quatro dias, sem transitar para o útero, sendo então recuperadas e transferidas a receptoras. Embora não aplicável do ponto de vista comercial, a taxa de gestação foi de $82,6 \%$ (19/23) e a de parição 94,7\% (18/ 19), com uma taxa de sobrevivência embrionária ao nascimento de $66,7 \%(32 / 48)$.

A técnica de produção de embriões in vitro se torna ainda mais pontual quando utilizada como ferramenta de clonagem. Embora o primeiro clone produzido a partir de transferência de núcleo de célula somática tenha sido da espécie ovina (Wilmut et al., 1997), os resultados de sobrevivência pós-natal de clones dessa espécie são igualmente baixos (Loi et al., 2006), comparativamente àqueles obtidos em bovinos e caprinos. Porém, resta o desafio de utilização do ovino como modelo animal em programas de produção de animais geneticamente modificados (Pereyra-Bonnet et al., 2008).

\section{Comentário finais}

Somados todos esses fatores à variabilidade biológica relacionada à qualidade e quantidade de oócitos passíveis de maturação, fertilização e desenvolvimento in vitro, e sua forma de obtenção, torna a FIV ovina, comparativante a bovina, um processo biotecnológico de custo elevado, mas que não a exclui como a possibilidade de multiplicação de animais geneticamentesuperiores. A rentabilidade final do processo em número de embriões transferidos e cordeiros saudáveis nascidos por doadora puncionada ainda é baixa, além de poder gerar fetos com gigantismo e/ ou complicações peri-natais que interfiram diretamente na sobrevida dos cordeiros. Trata-se de um desafio, que já apresenta os primeiros resultados com visão comercial em nosso país (Bosso et al., 2008), a partir de reprodutores e matrizes de reconhecido mérito genético, e em especial das raças Dorper e Santa Inês.

\section{Literatura Citada}

ACCARDo, C.; DATTENA, M; PILICHI, S. et al. Effect of recombinant human FSH and $\mathrm{LH}$ on in vitro maturation of sheep oocytes: embryo development and viability. Theriogenology, v.81, p.77-86, 2004.

ALBERIO, R.; OLIVERA,J.; ROCHE, A. et al. Performance of a modified ovum pick-up system using three different FSH stimulation protocols in ewes. Small Ruminant Research, v.46, p.81-87, 2002.

BALDASSARRE, H.; DE MATOS, D.G; FURNUS, C.C. et al. Technique for efficient recovery of sheep oocytes by laparoscopic folliculocentesis. Animal Reproduction Science, v. 35, p. $145-150,1994$.
BALDASSARRE, H.; FUMUS, C.C.; MATOS, D.G. et al. In Vitro production of sheep embryos using laparoscopic folliculocentesis: alternative gonadotrophin treatments for stimulation of oocyte donors. Theriogenology, v.45, p.707717, 1996.

BALDASSARRE, H.; WANG, B.; KAFIDI, N. et al. Advances in the production and propagation of transgenic goats using laparoscopic ovum pick-up and in vitro embryo production technologies. Theriogenology, v.57, p.275-284, 2002.

BALDASSARRE, H.; WANG, B.; KAFIDI, N. et al. Production of transgenic goats by pronuclear microinjection of in vitro produced zygotes derived from oocytes recovered by laparoscopy. Theriogenology, v.59, p.831-839, 2003.

BALDASSARRE, H.; KARATZAS, C.N. Advanced assisted reproduction technologies (ART) in goats. AnimalReproduction Science, v.82, p.255-266, 2004.

BASSO, C.A.; MARTINS, J.F.P.; FERREIRA, C.R. et al. Produção in vitro de embriões ovinos: aspectos da técnica de aspiração folicular e do tratamento hormonal de doadoras. O embrião, n.38, p.9-13, 2008.

COGNIÉ, Y. State of the art in sheep and goat embryo transfer. Theriogenology, v.15, p.105-116, 1999.

COGNIÉ Y.; BARIL, G.; POULIN, N. et al. Current status of embryo technologies in sheep and goat.Theriogenology, v.59, p.171$188,2003$.

COGNiÉ, Y.; POUlin, N.; LOCATELli, Y. et al. State of the art production, conservation and transfer of in vitro produced embryos in small ruminants. Reproduction, Fertility and Development, v.16, p.437-445, 2004.

COX, J.F.; ALFARO, V. In vitro fertilization and development of OPU derived goat and sheep oocytes. Reproduction of Domestic Animals, v.42, p.83-87, 2007.

CROZET, N.; AHMED-ALI, M.; DUBOS, M.P. Developmental competence of goat oocyte from follicles of different size categories following maturation, fertilization and culture in vitro. Journal of Reproduction and Fertility, v.103, p.293-298, 1995.

CROZET, N. In vitro generation of one cell embryos in sheep and goat. In: Transgenic animals: generation and use. Amsterdan: Hardwood Academic Publishers, 1997, 576p.

DURANTHON, V.; RENARD, J.P. The developmental competence of mammalian oocytes: a convenient but biologically fuzzy concept. Theriogenology, v.55, p.1277-1289, 2001.

FARIN, P.W.; CROSIER, A.E.; FARIN, C.E. Influence of in vitro systems on embryo survival and fetal development in cattle. Theriogenology, v.55, p.151-170, 2001.

GARCIA-GARCIA, R.M.; DOMINGUEZ, V.; GONZALEZBULNES, A. et al. Effect of embryo developmental stage and culture conditions on number and quality of ovine in vitro produced blastocysts Zygote, v.14, p.181-187, 2006.

GIBBONS, A.; PEREYRA BONNET, F.; CUETO, M. et al. A procedure for maximizing oocyte harvest for in vitro embryo production in small ruminants. Reproduction of Domestic Animals, v.42, p.423-426, 2007.

GIBBONS, A.; PEREYRA-BONNET, F.; CUETO, M. et al. Colheita de oócitos guiada por laparoscopia em caprinos e ovinos. Acta Scientiae Veterinariae, v.36 (supl. 2), p.223-230, 2008.

GULER, A.; POULIN, N.; MERMILLOD, P. et al. Effect of growth factors, EGF and IGF-1, and estradiol on in vitro maturation of sheep oocytes. Theriogenology, v.54, p.209-218, 2000.

HOLM, P.; WALKER, S.K.; SEAMARK, R.F. Embryo viability, duration of gestation and birth weight in sheep after transfer of in vitro matured and in vivo fertilized cultured in vitro or in vivo. Journal of Reproduction and Fertility, v.107, p.175$181,1996$.

KELLY, J.M.; KLEEMANN, D.O.; MAXWELL, W.M.C. et al. Effects of insulin-like growth factor-I, epidermal growth factor and cysteamine on the in vitro maturation and development of oocytes collected from 6- to 8-week-old Merino lambs. 
Reproduction, Fertility and Development, v.20, p.570-578, 2008.

KESKINTEPE, L.; DARWISH, C.M.; KENIMER, A.T. et al. Term development of caprine embryos derivated from immature oocytes in vitro. Theriogenology, v.42, p.527-535, 1994.

LEONI, G.G.; ROSATI, I.; SUCCU, S. et al. A low oxygen atmosphere during IVF accelerates the kinetic of formation of in vitro produced ovine blastocysts. Reproduction of Domestic Animals, v.42, p.299-304, 2007.

LOI, P.; Clinton, M.; VACKOVA, I. et al. Placental abnormalities associated with post-natal mortality in sheep somatic cell clones. Theriogenology, v.65, p.1110-1121, 2006.

MERMILlod, P.; LONERGAN, P.; CAROLAN, C. et al. Maturation ovocytaire in vitro chez les ruminants domestiques. Contraceptition Fertililité Sexualité, v.24, n.7-8, p.552$558,1996$.

MERMILLOD, P.; OUSSAID, B.; COGNIÉ, Y. Aspects of follicular and oocyte maturation that affect the developmental potential of embryos. Journal of Reproduction and Fertility, v. 54, p.449-460, 1999.

MERMILLOD, P.; DALBIÈS-TRAN, R.; UZBEKOVA, S. et al. Factors affecting oocyte quality: who is driving the follicle? Reproduction of Domestic Animals, v.43 (suppl. 2), p.393400, 2008.

MORTON, K.M.; DE GRAAF, S.P.; CAMPBELL, A. et al. Repeated ovum pick-up and in vitro embryo production from adult ewes with and without FSH treatment. Reproduction of Domestic Animals, v.40, p.422-428, 2005a.

MORTON, K.M.; CATT, S.L.; MAXWELL, W.M.C. et al.In vitro and in vivo developmental capabilities and kinetics of in vitro development of in vitro matured oocytes from adult, unstimulated and hormone-stimulated prepubertal ewes. Theriogenology, v.64, p.1320-1332, 2005b.

MORTON, K.M.; MAXWELL, W.M.C.; EVANS, G. Effect of aspiration pressure during oocyte harvesting on oocyte recovery and in vitro development of ovine oocytes. Reproduction of Domestic Animals, v.43, p.106-110, 2008.

PALMIERI, C.; LOI, P.; REYNOLDS, L.P. et al. Placental abnormalities in ovine somatic cell clones at term: a light and electron microscopic investigation. Placenta, v.28, p.577$584,2007$.

PTAK, G.; FEDERICA LOPES, F.; KAZUTSUGU MATSUKAW, $K$. et al. Leukaemia inhibitory factor enhances sheep fertilization in vitro via an influence on the oocyte. Theriogenology, v.65, p.1891-1899, 2006.

PEREYRA-BONNET, F.; FERNÁNDEZ-MARTÍN, R.; OLIVERA, R. et al. A unique method to produce transgenic embryos in ovine, porcine, feline, bovine and equine species. Reproduction, Fertility and Development, v.20, p.741-749, 2008.

PIERSON, J.; WANG, B.; NEVEU, N. et al. Effects of repetition, interval between treatments and season on the results from laparoscopic ovumpick-up in goats. Reproduction, Fertility and Development, v.16, p.795-799, 2004

REGGIO, B.C.; JAMES, A.N.; GREEN, H.L. et al. Cloned transgenic offspring resulting from somatic cell nuclear transfer in the goat: oocytes derived from both follicle-stimulating hormonestimulated and nonstimulated abattoir-derived ovaries. Biology of Reproduction, v.65, p.1528-1533, 2001.

RIZOS, D.; FAIR, T.; PAPADOPOULUS, S. et al. Developmental, qualitative and ultrastructural differences between bovine and ovine embryos produced in vivo or in vitro. Molecular Reproduction Development, v.62, p.320-327, 2002.

RODRÍGUEZ, C.; ANEL, L.; ALVAREZ, M. et al. Ovum pick-up in sheep: a comparison between different aspiration devices for optimal oocyte retrieval. Reproduction of Domestic Animals, v.41, p.106-113, 2006.

SINCLAIR, K.D.; McEVOY, T.G.; MAXFIELD, E.K. et al. Aberrant fetal growth and development after in vitro culture of sheep zygotes. Journal of Reproduction and Fertility, v.116, p.177-186, 1999.

SNYDER, D.A.; DUKELOW, R. Laparoscopic studies of ovulation, pregnancy diagnosis and follicle aspiration in sheep. Theriogenology, v.2, p.143-148, 1974.

TERVIT, H.R.; SMITH, J.F.; McGOWAN, L.T. et al.Laparoscopic recovery of oocytes from sheep. S.L.: Australian Society of Reproductive Biology, 1992. v.24, p.26.

THOMPSON, J.G.; GARDNER, D.K.; PUGH, P.A. et al. Lamb birth weight is affected by culture system utilized during in vitro preelongation development of ovine embryos. Theriogenology, v.45, p.27-40, 1995.

THOMPSON, J.G. In vitro culture and embryo metabolism of cattle and sheep embryos - a decade of achievement. Animal Reproduction Science, v.60-61, p.263-275, 2000.

TRALDI, A.S.; LEBOEUF, B.; COGNIE, Y. et al.Comparative results of in vitro and in vivo survival of vitrified in vitro produced goat and sheep. Theriogenology, v.51, p.175, 1999. 